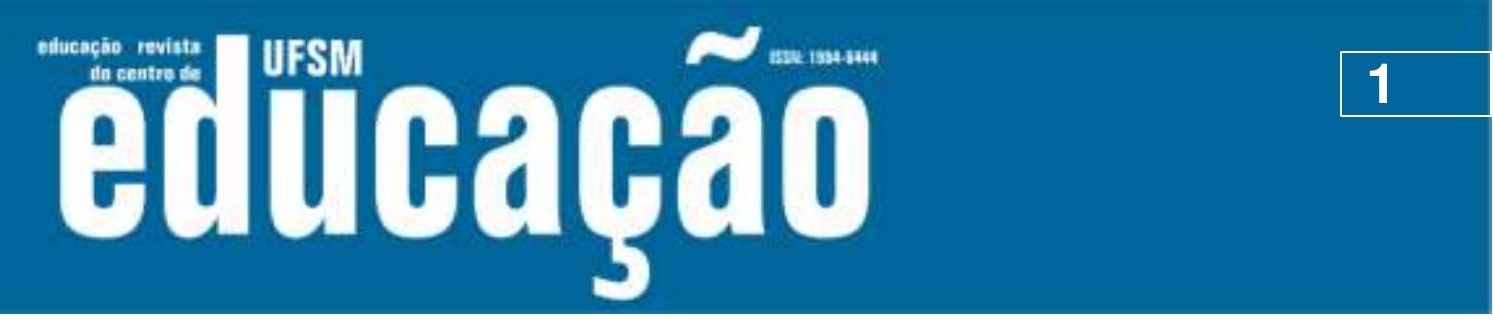

ISSN: 1984-6444 | http://dx.doi.org/10.5902/1984644432996

\title{
Movimento Escola Sem Partido: uma leitura à luz de Paulo Freire
}

\author{
Unpolitical Schools Movement and the ideas of Paulo Freire
}

Heli Sabino de Oliveira

Professor Adjunto de História da Faculdade de Educação da Universidade Federal de Minas Gerais, Belo Horizonte, Minas Gerais, Brasil.

\section{Débora Mariz}

Professora Adjunta de Filosofia da Faculdade de Educação da Universidade Federal de Minas Gerais, Belo Horizonte, Minas Gerais, Brasil.

Endereço: Universidade Federal de Minas Gerais, Faculdade de Educação. Av. Pres. Antônio Carlos, 6627. Pampulha. CEP: 3127090. Belo Horizonte, Minas Gerais, Brasil. E-mail: deboramariz@gmail.com - helisabino@yahoo.com.br

Recebido em 08 de junho de 2018

Aprovado em 17 de setembro de 2018

\section{RESUMO}

Este trabalho visa analisar um dos fundamentos do Movimento Escola Sem Partido para contrapor o pensamento de Paulo Freire, a saber: o pressuposto da neutralidade do educador.Para tanto, será realizada uma pesquisa bibliográfica, de caráter qualitativo em que serão utilizados três eixos interpretativos: (1) a concepção de neutralidade a partir do paradigma científico e seus desdobramentos na educação, (2) a relação entre educação e política e (3) a concepção freireana de leitura do mundo. Pretende-se, assim, confrontar alguns pressupostos do referido Movimento, especialmente no que concerne à pretensa neutralidade do educador com a concepção freireana de educação. Enquanto o pensamento freireano nos faz estranhar as práticas sociais, o Movimento Escola Sem Partido busca naturalizar o mundo social, o que justifica, em parte, a sua aversão ao pensamento de Paulo Freire, que se baseia em um mundo plural, em disputa por recursos simbólicos e materiais. Palavras-chave: Paulo Freire; Escola Sem Partido;Neutralidade. 


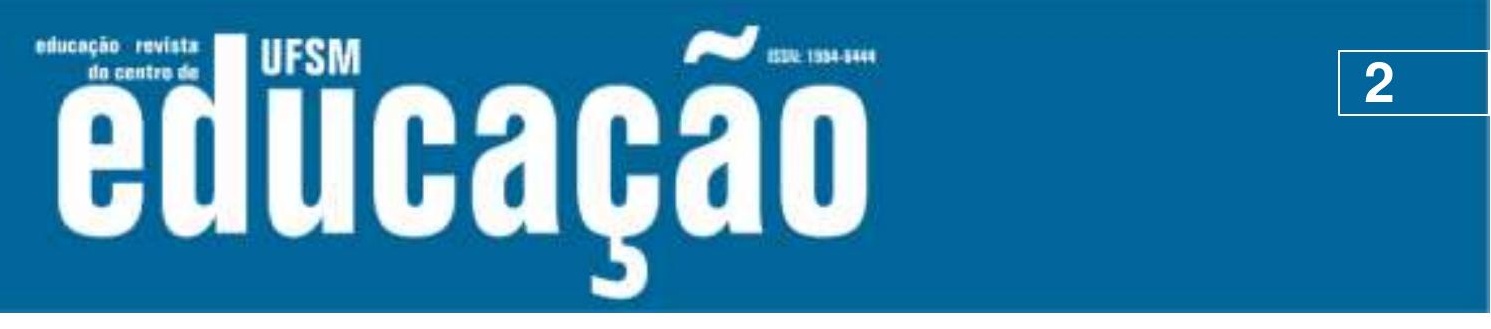

ISSN: 1984-6444 | http://dx.doi.org/10.5902/1984644432996

\section{ABSTRACT}

This paper aims at analyzing the foundations of the Unpolitical Schools Movement to criticize the thought of Paulo Freire, namely: the assumption of the neutrality of the educator. To do so, a qualitative bibliographical research will be carried out in which three interpretative axes will be used: (1) the conception of neutrality from the scientific paradigm and its consequences in education; (2) the relationship between education and politics; (3) Freire's conception of reading the world. It is intended, therefore, to confront some of the assumptions of this Movement, especially regarding the alleged neutrality of the educator with the Freirean conception of education. While Freire's thought makes us strange to social practices, the Unpolitical Schools Movement seeks to naturalize the social world, which partly justifies its aversion to the thinking of Paulo Freire that is based on a plural world, in dispute for symbolic and material resources.

Keywords: Paulo Freire; Unpolitical Schools Movement; Neutrality.

\section{Introdução}

Seria Paulo Freire um "doutrinador ideológico, dogmático e autoritário", como afirma Diniz Filho (2013), um dos apoiadores do Movimento Escola Sem Partido? Por que o Movimento Escola Sem Partido se insurge contra o pensador Paulo Freire, procurando caçar seu título de patrono da educação brasileira ${ }^{1}$ Em que medida o pensamento de Paulo Freire desafia os fundamentos do Movimento Escola Sem Partido?

Este trabalho visa analisar os fundamentos do Movimento Escola Sem Partido à luz do pensamento freireano². Para tanto, utilizaremos três eixos interpretativos: (1)

\footnotetext{
1 O título de patrono da educação brasileira foi outorgado pela PL 12612, em 13 de abril de 2012. Integrantes do Movimento Escola Sem Partido, sob alegação de que se trata de um filósofo de esquerda, cujo método tem sido responsável pelos resultados educacionais catastróficos, solicitam, no entanto, que o referido título fosse cassado pelo Congresso Nacional. Disponível em: https://www.carosamigos.com.br/index.php/cotidiano/10862-proposta-quer-retirar-o-titulo-de-patronoda-educacao-de-paulo-freire. Acesso em: 29 out. 17. Todavia, a Comissão de Direitos Humanos e Legislação Participativa do Senado (CDH) rejeitou, em 14/12/2017, a sugestão legislativa (SUG 47/2017) que visava a cassação do título de patrono da educação brasileira a Paulo Freire. Disponível em: https://www12.senado.leg.br/noticias/audios/2017/12/cdh-rejeita-sugestao-de-retirar-de-paulofreire-o-titulo-de-patrono-da-educacao. Acesso em: 23ago.18.

2 Utilizaremos o termo "Movimento" para se referir ao Movimento Escola Sem Partido por compreender que não se trata apenas de uma proposta de projeto político definido, mas sim de um movimento social decorrente da organização civil de um grupo que busca uma determinada transformação social e está voltado para a realização de objetivos comuns, sob orientação, mais ou menos consciente, de princípios compartilhados e com uma organização diretiva definida. Para uma discussão detalhada desse tema, ver: GOHN, 1997.
} 


\title{
Lusm

ISSN: 1984-6444 | http://dx.doi.org/10.5902/1984644432996

sentido, a ciência não se deixaria influenciar pelos valores sociais durante a seleção dos fenômenos a serem investigados; nem durante a escolha das teorias para explicálas e nem na elaboração dos conteúdos das proposições científicas. Para tanto, essa neutralidade se fundamenta em três argumentos, a saber:

\begin{abstract}
1 Tese da neutralidade temática: a ciência é neutra porque o direcionamento da pesquisa científica, isto é, a escolha dos temas e problemas a serem investigados, responde apenas ao interesse em desenvolver o conhecimento como um fim em si mesmo.
\end{abstract}

2 Tese da neutralidade metodológica: a ciência é neutra porque procede de acordo com o método científico, segundo o qual a escolha racional entre as teorias não deve envolver e, de maneira geral, não tem envolvido valores sociais.

3 Tese da neutralidade factual: a ciência é neutra porque não envolve juízos de valor; ela apenas descreve a realidade, sem fazer prescrições; suas proposições são puramente factuais. (OLIVEIRA, 2008, p.98).

Contudo, essa pretensa neutralidade da ciência culminou com uma representação e explicação da realidade destituída de um horizonte de sentido para a vida, ou seja, os avanços científicos e tecnológicos, pautados nessa pretensa independência da ciência em relação aos valores, fez com que a ciência se distanciasse do mundo da vida, afastando-se da dimensão ética de seu fazer, do mundo dos valores e da experiência humana, tendo como ápice uma crise das ciências ${ }^{5}$. A esse respeito, Lacey (2009) afirma que todo o discurso e ação humana são permeados de uma racionalidade espontânea que ultrapassa a racionalidade científica, entendida como um sistema fechado e descontextualizado do mundo da vida.

O autor explicita ainda, em artigo posterior, que a investigação imparcial das ciências não exclui a responsabilidade dos cientistas, pois estes devem considerar os valores éticos e sociais de papeis indispensáveis na pesquisa científica e estes valores são relevantes para as deliberações democráticas (LACEY, 2011).

Um desdobramento dessa discussão leva-nos à compreensão de que a neutralidade factual diz respeito à imparcialidade presente na descrição dos fatos científicos, própria à racionalidade científica. Contudo, isso não implica necessariamente em uma neutralidade temática e metodológica, pois existem valores

\footnotetext{
${ }^{5}$ A respeito dessa crise das ciências ver as reflexões do filósofo alemão Edmund Husserl (2002).
} 


\section{Lusm Alltapato}

ISSN: 1984-6444 | http://dx.doi.org/10.5902/1984644432996

que orientam a escolha de determinadas investigações, como os valores subjetivos, econômicos e políticos. Além disso, a escolha de um método em detrimento de outro, usado para explicar determinada teoria, pressupõe também valores sociais implícitos.

Uma vez entendida que a neutralidade da ciência não implica uma ausência de valores, retomamos a discussão sobre a neutralidade na educação defendida pelo Movimento Escola sem Partido.

Poderíamos pressupor que essa neutralidade do professor seja uma neutralidade factual em que ele seria um transmissor da racionalidade científica, isto é, de um saber puramente racional e objetivo. Assim entendido, a prática pedagógica, na perspectiva da neutralidade, seria uma prática tradicionalista em que o professor sabe e ensina e o aluno não sabe e aprende. Sendo este último depositário de saberes que o professor lhe transmitirá e este deverá devolver exatamente como lhe foi transmitido. O que será avaliado e mensurado consistirá rigorosamente na quantidade de informações que foram apreendidas e reproduzidas, de acordo com as exigências do professor. O comportamento do aluno será, muitas vezes, determinado por normas rígidas, em que ele deverá controlar as suas emoções, a sua imaginação, a sua sensibilidade e a sua afetividade ${ }^{6}$.

Ora, assim como a neutralidade da ciência não implica uma ausência de valores, a suposta neutralidade na educação não pode desconsiderar esses valores; eis aí um problema fundamental no discurso do Movimento Escola sem Partido: a desconsideração da dimensão valorativa de toda ação humana, isto é, sua dimensão ética.

A esse respeito, Paulo Freire foi enfático ao afirmar uma ética universal do ser humano, enquanto marca característica de nosso ser no mundo, em relação com os outros seres e com o próprio mundo. Em decorrência disso, ele afirmará a natureza ética da prática educativa que implica uma congruência entre seu preparo científico e sua retidão ética. Isso por entender que "formação científica, correção ética, respeito aos outros, coerência, capacidade de viver e de aprender com o diferente" são

\footnotetext{
${ }^{6}$ Cf. BERTRAND; VALOIS, 2005, p. 101. Para esses autores, esta prática pedagógica é própria do paradigma tecnológico e, embora não utilizem o termo positivista, concebemos que a origem desse paradigma é o positivismo.
} 


\section{Us:

ISSN: 1984-6444 | http://dx.doi.org/10.5902/1984644432996

indispensáveis à convivência humana e, consequentemente, à vida escolar (FREIRE, 2017, p.18).

O ser humano, ao relacionar-se com os outros e com a natureza, transformou a própria natureza em sua morada, criou cultura, criou valores, criou linguagem. $\mathrm{O}$ conhecimento é uma construção humana e, como tal, não pode ser destituído de valor: não existe conhecimento neutro, assim como não existe educação neutra, visto que todo conhecer, todo aprender, todo agir no mundo está imerso de significação pela própria dimensão constitutiva do ser humano. Ninguém escolhe só por escolher, ninguém faz só por fazer, pois estas ações trazem em si mesmas toda a bagagem de valores que constitui nossa humanidade,bem como o contexto ao qual estamos inseridos.

Tanto a prática científica quanto a prática pedagógica estão prenhes dos valores do contexto em que elas se realizam. Mesmo que um profissional da educação que atue dentro de e a partir de uma perspectiva de neutralidade afirme a sua desvinculação de qualquer tipo de valores, estará, implicitamente, fazendo uma opção pelo status quo, pois é impossível alguém não ter valor, ser amoral. A sua falta de desvinculação já mostra um valor, aquele da moralidade da instituição em que trabalha.

A educação, como reprodutora do status quo, também foi objeto de análise de denúncia de Paulo Freire (2003). Isso porque ela seria fonte de conformismo, falta de compromisso e desorganização do processo educacional. Se o educador tem dificuldades em perceber sua tarefa cotidiana como uma ação histórica e política, a educação que realiza se reduz a uma mera transmissão de informações, sem procurar saber por quê, para quê e para quem ela se direciona. O não posicionamento do professor não implica que ele sejaneutro, mas que ele deixou-se guiar por escolhas alheias ao seu próprio agir, aos seus próprios valores, enfim, renunciou à sua autonomia.

Passemos agora ao segundo eixo da discussão: a relação entre educação e política.

\section{Educação e política}




\section{U usm oitibabat}

ISSN: 1984-6444 | http://dx.doi.org/10.5902/1984644432996

Em várias postagens, em sua página no Facebook, o Movimento Escola Sem Partido dissocia educação de ensino e educação de política ${ }^{7}$. A articulação desses termos produz, na visão desse movimento, duas consequências nefastas para o processo de escolarização: a) redução da qualidade do ensino, conforme dados aferidos pelo Programa Internacional de Avaliação de Estudantes (PISA) e Avaliação Nacional do Rendimento Escolar, conhecida como Prova Brasil; b) perda do caráter instrutivo do ensino, facilitando o agenciamento de práticas doutrinárias e ideológicas em sala de aula.

Do ponto de vista teórico, o Movimento Escola Sem Partido se vale do pensamento do desconhecido filósofo Armindo Moreira ${ }^{8}$. Sua obra, Professor não é Educador, amplamente divulgada na rede social pelos adeptos do Movimento dá o tom do debate. Para Moreira (2013), enquanto a educação diz respeito à promoção de sentimentos e hábitos que permitam ao indivíduo se adaptar ao meio em que vive, a instrução se refere à questão de transferência de conhecimentos e habilidades que assegurem às pessoas formas de se inserirem, de maneira competente, no mercado de trabalho.

(...) cruzamos na vida com pessoas instruídas e mal educadas; e conhecemos analfabetos com esmerada educação. A instrução, por si mesma, não dá felicidade. Porém é difícil conceber que um homem bem educado venha a ser infeliz. Sabemos que os jovens e as crianças podem sofrer motivações de várias pessoas. Porém só educa eficazmente quem ama o educando. Sendo assim, o professor teria de amar os educandos, para poder educá-los. E o que poderia motivar o professor a amar os seus alunos: o salário? (MOREIRA, 2013, p.31).

O pensamento de Moreira, celebrado pelo Movimento Escola Sem Partido, limita, dessa forma, a função da escola à difusão de conhecimentos técnicos instrumentais. Sua ênfase incide sobre habilidades procedimentais (habilidade de leitura, escrita e cálculos matemáticos, por exemplo), não permitindo que se indague sobre o sentido dos saberes escolares nas práticas sociais, nem sobre os lugares ocupados pela técnica no processo de estratificação da sociedade. Trata-se, assim,

\footnotetext{
7 Disponível em: https://pt-br.facebook.com/escolasempartidooficial/. Acesso em: 27 ago. 2018.

$8 \mathrm{http}: / /$ www.escolasempartido.org/educacao-moral/415-professor-nao-e-educador
} 


\section{U usm Autthabat}

ISSN: 1984-6444 | http://dx.doi.org/10.5902/1984644432996

de uma visão pedagógica tecnicista e reprodutivista, amplamente difundida na educação brasileira na década de 1960 e $1970^{9}$.

O conceito de educação, apresentado por Moreira (2013) possui, por sua vez, um caráter reducionista. Em vez de ser compreendida como processos formativos que se desenvolvem, dentre outros espaços, nas relações familiares, no trabalho, movimentos sociais, organizações da sociedade civil, manifestações culturais instituições de ensino e pesquisa e escola, a educação é pensada como uma matéria que se circunscreve, de forma exclusiva, no seio familiar. Educar é, para ele, um ato de amor, algo impensável para profissionais que possuem parcos salários. Com efeito, o intuito dos professores, ao defender o caráter educativo da escola, é promover a doutrinação marxista, inserindo elemento estranho à escolarização: a partidarização política.

Em Paulo Freire, educação e ensino e educação e política são elementos indissociáveis. Daí a aversão do Movimento Escola Sem Partido a esse pensador. No entanto, pode-se afirmar que a dimensão política da escola remonta à Grécia Antiga.

Platão, em sua República, já evidenciava a importância de uma sociedade justa, fundamentada na educação de seus membros. Aristóteles, em sua Política, apresenta três características específicas do homem que o distinguem dos demais animais: a fala, as qualidades éticas e a comunicação. A primeira qualidade, a fala, possibilita indicar não somente a dor e o prazer, mas também o justo e o injusto. As qualidades éticas possibilitam a percepção do bem e do mal, bem como do justo e do injusto (Pol. I, 1, 1253a 14-18). E, conclui Aristóteles, "a comunicação faz a casa e a cidade." (Pol. I, 1, 1253a 18-19). Aristóteles dirá que o homem é um animal político e a finalidade da política consiste em organizar a sociedade, de tal modo que nela se possa viver uma vida virtuosa e feliz e não apenas materialmente confortável. Para tanto, é preciso que o ser humano tenha a capacidade de discernimento, através da educação, distinguindo racionalmente o útil do inútil, o verdadeiro do falso, o justo do injusto.

${ }^{9}$ Para uma compreensão detalhada dessa visão, ver SAVIANI, Dermeval. Escola e Democracia. 42ed. São Paulo: Autores Associados, 2018. 


\section{U usm Autlaahã

ISSN: 1984-6444 | http://dx.doi.org/10.5902/1984644432996

Por essa via, a política se dá como uma prática racionalmente orientada para a construção e manutenção do bem comum. Essa concepção de política é enfatizada nas obras de Paulo Freire, especialmente na Pedagogia da Autonomia, último trabalho publicado pelo autor em vida.

$\mathrm{Na}$ concepção pedagógica freireana, pode-se dizer que existem saberes indispensáveis aos educadores e um deles reside no fato de que ensinar não é transferir conhecimento, mas criar possibilidades para a sua construção. Para tanto, é imprescindível a experiência dos educandos que podem refazer/recriar o ensinado, apropriando-se desse saber no contexto de sua própria realidade.Freire sustenta que a prática educativa precisa se assentar no diálogo e na problematização, por meio de perguntas destabilizadoras, que despertem curiosidades e que provoquem novos desafios aos educandos.

Freire rejeita qualquer proposta educativa que apresente o educador como facilitador do processo pedagógico, como um mediador, cuja principal tarefa seja transferência de conhecimentos. Para ele, subjacente à concepção de transferência de conteúdo, celebrada pelos modismos pedagógicos, encontra-se a noção de que conhecimento é uma coisa ou abstração, com vida própria, sem conexão com indivíduo e sociedade.Todavia, o conhecimento não é, para ele, uma entidade autônoma e neutra, nem um elemento reificado da cultura e da sociedade.

Pode-se dizer que Paulo Freirecompreende o conhecimento como uma construção social, fruto de relações de poder. Com efeito, não se trata apenas de uma construção técnica, guiada por princípios epistemológicos e regras metodológicas. caráter inescapavelmente político e ideológico do conhecimento esconde, todavia, intenções e interesses. Portanto, questionar relações de saber e de poder é algo inerente às práticas pedagógicas emancipatórias. Afinal de contas, o conhecimento precisa ser pensado em favor de quê, de quem ou contra o quê e contra quem.

Em uma passagem da Pedagogia da Autonomia, Freire (2017, p.21) sugere, de maneira explícita, que o professor tome, como objeto de reflexão, em sala de aula, experiências discentes em áreas periféricas dos grandes centros urbanos. Tendo como foco de observação aspectos da cidade negligenciados pelo poder público, Freire sugere que se discuta com alunos a questão da poluição dos riachos e dos 


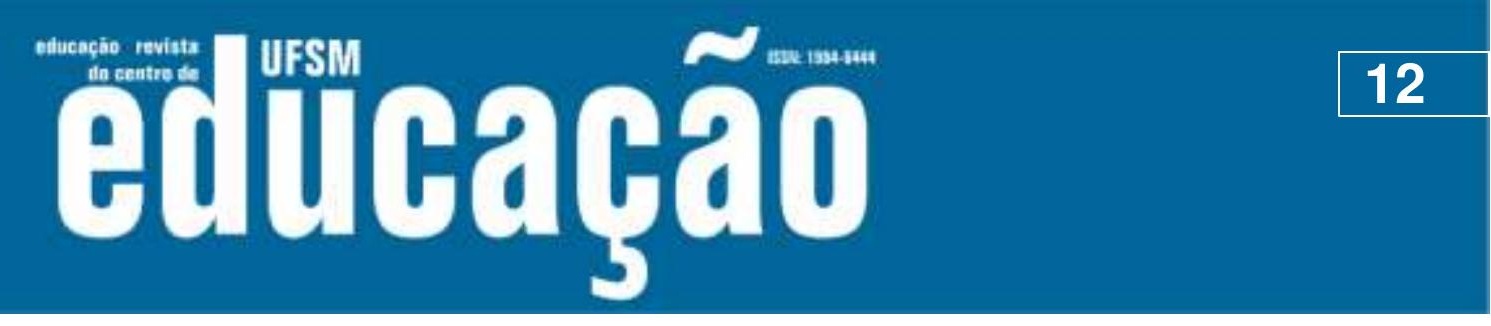

ISSN: 1984-6444 | http://dx.doi.org/10.5902/1984644432996

córregos e dos baixos níveis de bem-estar das populações, bem como a presença de lixões e os riscos que oferecem à saúde das pessoas. Trata-se, pois, de uma abordagem dialógica e problematizadora, que tem como cerne o questionamento de relações de poder.

Por que não há lixões no coração dos bairros ricos e mesmo puramente remediados dos centros urbanos? Esta pergunta é considerada em si demagógica e reveladora da má vontade de quem a faz. É pergunta de subversivo, dizem certos defensores da democracia. Por que não discutir com os alunos a realidade concreta a que se deva associar a disciplina cujo conteúdo se ensina, a realidade agressiva em que a violência é a constante e a convivência das pessoas é muito maior com a morte do que com a vida? Por que não estabelecer uma necessária "intimidade" entre os saberes curriculares fundamentais aos alunos e a experiência social que eles têm como indivíduos? Por que não discutir as implicações políticas e ideológicas de um tal descaso dos dominantes pelas áreas pobres da cidade? Que ética de classe está embutida neste descaso? (FREIRE, 2017, p. 32).

Como pensador dialógico, Freire constrói, nessa passagem, um suposto interlocutor conservador, que questionará esse tipo de abordagem.

(...) dirá um educador reacionariamente pragmático, a escola não tem nada que ver com isso. A escola não é partido. Ela tem que ensinar os conteúdos, transferí-los aos alunos. Aprendidos, estes operam por si mesmos (FREIRE, 2017, p.31-32) Grifo nosso.

Observa-se aqui que o interlocutor idealizado por Freire possui uma visão de mundo que nos remete ao Movimento Escola Sem Partido, negando a dimensão educativa e política da escola. Em outra passagem, o autor enfatiza o caráter astuto da ideologia dominante, que defende um processo de escolarização neutro, sem ideologia política.

Creio que nunca precisou o professor progressista estar tão advertido quanto hoje em face da esperteza com que a ideologia dominante insinua a neutralidade da educação. Desse ponto de vista, que é reacionário, o espaço pedagógico, neutro por excelência, é aquele em que se treinam os alunos para práticas apolíticas, como se a maneira humana de estar no mundo fosse ou pudesse ser uma maneira neutra. Minha presença de professor, que não pode passar despercebida dos alunos na classe e na escola, é uma presença em si política. Enquanto presença não posso ser uma omissão, mas um sujeito de opções. Devo revelar aos alunos a minha capacidade de analisar, de comparar, de avaliar, de decidir, de optar, de romper. Minha capacidade de fazer justiça, de não falhar à verdade. Ético, por isso mesmo, tem que ser o meu testemunho (FREIRE, 2017, p.95-96).

Cumpre sublinhar que a dimensão política, defendida por Freire, está estritamente ligada ao respeito à diversidade dos educandos e educadores, dos gestores e da comunidade escolar, à luta em favor da vida e da dignidade humana. 


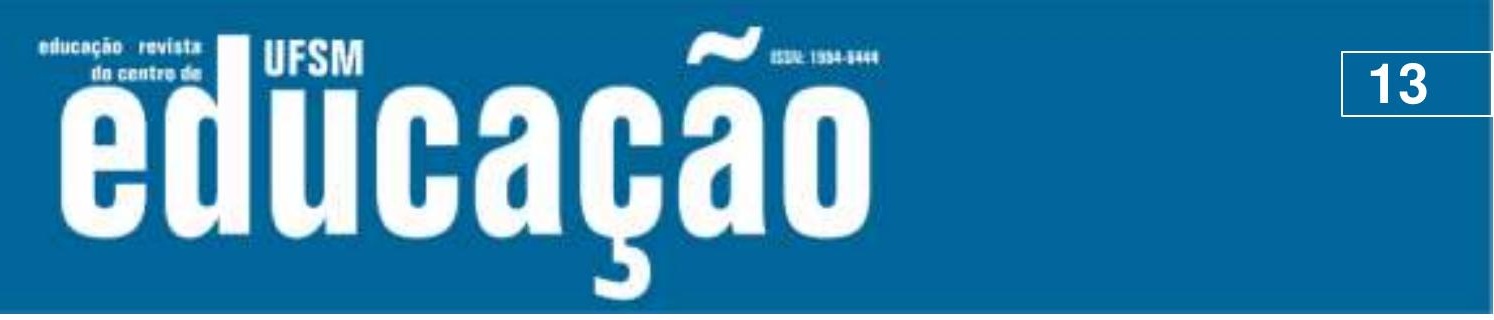

ISSN: 1984-6444 | http://dx.doi.org/10.5902/1984644432996

Em outras palavras, a dimensão política sustentada por Freire é aversa a qualquer forma de dogmatismo e doutrinação, fundamentando-se em princípios éticos que respeitem à dignidade humana e ao direito à diferença.

Lutar pelo direito que tenho de ser respeitado e pelo dever que tenho de reagir
a que me destratem. Lutar pelo direito que você, que me lê, professora ou
aluna, tem de ser você mesma e nunca, jamais, lutar por essa coisa
impossível, acinzentada e insossa que é a neutralidade. Que é mesmo a
minha neutralidade senão a maneira cômoda, talvez, mas hipócrita, de
esconder minha opção ou meu medo de acusar a injustiça? 'Lavar as mãos'
em face da opressão é reforçar o poder do opressor, é optar por ele. Como
posso ser neutro diante da situação, não importa qual seja ela, em que o
corpo das mulheres e dos homens vira puro objeto de espoliação e descaso?
O que se coloca à educadora ou educador democrático, consciente da
impossibilidade da neutralidade da educação, é forjar em si um saber
especial, que jamais deve abandonar, saber que motiva e sustenta sua luta:
se a educação não pode tudo, alguma coisa fundamental a educação pode
(FREIRE, 2017, p.70).

Nessa perspectiva, a educação é, antes de tudo, uma ferramenta de luta, um instrumento de combate às injustiças sociais e às desigualdades.

Passemos, então, ao terceiro momento de nossa análise, a saber: a leitura do mundo.

\section{A leitura de mundo}

A leitura de mundo é um dos fundamentos do pensamento freireano. Uma escola que se concentra em apenas apresentar a leitura da palavra, divorciada do contexto de sua produção, busca apenas conservar o status quo, não colocando em xeque as hierarquias e interesses que sustentam uma determinada forma de pensar e agir sobre o real. Como exemplo, pode-se citar três atividades corriqueiras que marcam o cotidiano das pessoas: ver fotografia, assistir reportagem pela TV e fazer compras no supermercado.

Silva (2000, p.15) sublinha que um dos grandes equívocos do positivismo é a crença de que a palavra apenas descreve o real, sem nenhuma relação com sua produção e conservação. Para o autor, o significante não captura o significado em toda sua plenitude. Desconsiderar isso é supor que o real possa ser apreendido de forma mimética ou analógica, algo que não acontece nem com a fotografia que captura, com realismo, o mundo. Aí, o ângulo, a luz, o corte, a edição são dispositivos usados pelo fotógrafo, alterando o real. Dessa forma, ao invés de reproduzir, de forma 


\section{U usm Autthabat

ISSN: 1984-6444 | http://dx.doi.org/10.5902/1984644432996

fidedigna, a realidade, a fotografia institui visões particulares acerca do mundo social e natural.

Muniz Sodré (1987, p.61) destaca o caráter interessado da transmissão de uma reportagem, mesmo em uma transmissão direta. Além da seleção das imagens no monitor, uma reportagem sofre cortes arbitrários: primeiro do cinegrafista que seleciona os ângulos de filmagem, alternando os closes; depois dos editores, que definem o que será exibido. Para o autor, a TV impõe ao receptor a sua especialíssima maneira de ver o real.

Carlos Eduardo Novaes (1997) destaca que não somente as palavras que precisam ser lidas nos supermercados, mas principalmente sua organização, a disposição de seus produtos nas prateleiras. Para ele, nesses estabelecimentos, o ordenamento dos artigos de consumo busca induzir os consumidores a comprar mais do que as pessoas realmente precisam. Assim, os gêneros de primeira necessidade ficam nos fundos, obrigando o indivíduo a entrar em contato com outros produtos. Enquanto as mercadorias supérfluas ficam à altura dos olhos, os materiais de limpeza e higiene pessoal ficam na parte de baixo das prateleiras. Os artigos enlatados e nocivos à saúde possuem embalagens sedutoras, com imagens e dizeres que estimulam o desejo de consumir tais produtos. Nem mesmo a presença da padaria no fundo dos supermercados é algo desinteressado. Sua instalação, nesse estabelecimento, é fruto do resultado de estudos que demonstram que o cheiro do pão desencadeia no cérebro humano o desejo de se alimentar. Ou seja, o pão assado deixa de ser, no supermercado, apenas um alimento, para se tornar uma estratégia de venda.

Assim, o ato de ler não se restringe apenas àquestão de decodificação da palavra, como defende o Movimento Escola Sem Partido. Para Freire, a leitura de mundo precede a leitura da palavra. Isso significa que ler é um ato de reescrever o texto, uma busca permanente para compreender suas articulações com o contexto social, político e econômico. Para o autor, ler é, acima de tudo, uma forma de reescrever, de transformar o texto através de uma prática consciente. Nas palavras de Freire: linguagem e realidade se prendem dinamicamente. A compreensão do texto 


\section{Lusm \\ 2.

ISSN: 1984-6444 | http://dx.doi.org/10.5902/1984644432996

a ser alcançada por sua leitura crítica implica a percepção das relações entre o texto e o contexto.

Paulo Freire contribui, assim, para o aprofundamento de uma questão epistemológica: a leitura de mundo. Do ponto de vista freireano, o conhecimento é sempre "intencionado", isto é, está sempre direcionado para alguma coisa. Essa intencionalidade aproxima-se da compreensão de "intencionalidade da consciência" do filósofo alemão Edmund Husserl ${ }^{10}$. Para esse filósofo,devemos voltar às coisas mesmas, não mais concebidas como fatos, mas como sentido construído na própria correlação entre o fenômeno (o que aparece) e a minha consciência desse fenômeno (o que aparece para mim). Daí afirmar que "toda consciência é consciência de algo" (HUSSERL, 2012). Isso implica o caráter intersubjetivo de nossa consciência, decorrente de nossa relação com o mundo da vida, isto é, com o mundo comunicativo, natural, intuitivo e estético da experiência. Nesse sentido, o mundo da vida é tudo aquilo que pode ser intuído por nós e é fundamento do sentido.

Cabe destacar que o ato de conhecer também não é visto por Paulo Freire como ato isolado, individual. Pelo contrário, conhecer envolve intercomunicações, intersubjetividade. Nessa concepção, os seres humanos mutuamente se educam, intermediados pelo mundo cognoscível. Por essa razão, Freire (2001) concebe o ato pedagógico como ato dialógico. O que não acontece com a chamada educação bancária, pedagogia voltada para subjugação e domesticação dos educandos. Aqui, o processo educativo se baseia na informação de conceitos e dados descolados das experiências imediatas do educando.

Segundo Freire (1981, p. 5), o conhecimento está articulado a questões como "conhecer em favor de quê? conhecer em favor de quem?" O que vale dizer: conhecer contra quê? Conhecer contra quem? Para Paulo Freire, não existe conhecimento neutro. $\mathrm{O}$ que faz com que $\mathrm{o}$ ato de conhecer se torne um ato político.

\footnotetext{
${ }^{10}$ A compreensão fenomenológica de Husserl busca uma via intermediária entre o subjetivismo e o objetivismo para compreender o modo pelo qual conhecemos as coisas. Nesse sentido, ele defende que o conhecimento não depende exclusivamente de uma racionalidade inata ou de uma razão absolutamente segura de seus pressupostos cognitivos, nem tampouco depende exclusivamente do modo pelo qual as coisas nos impelem a conhecê-las pela linguagem e pelos sentidos( OLIVEIRA, 2008a).
} 


\section{U Us: \\ 2.

ISSN: 1984-6444 | http://dx.doi.org/10.5902/1984644432996

$\mathrm{Na}$ perspectiva freireana, o conhecimento está estritamente ligado à possibilidade de transformação das condições sociais a que estão submetidos os grupos socialmente desfavorecidos. Nessa concepção, está implícita a suposição de que o conhecimento "descobre" o real, assegurando a passagem de um conhecimento ingênuo, caracterizado pelo misticismo e superstições, para um conhecimento crítico. Não se trata, no entanto, de um saber doado por especialistas e grupos de vanguardas para os educandos, como acontece nas propostas autoritárias. O que se busca na concepção freireana é a construção de um saber forjado com o discente. A função do educador é criar condições para que o educando sistematize o conhecimento. Nas palavras de Paulo Freire (1989, p. 25), o conhecimento sistematizado é indispensável à luta popular. Ele vai facilitar os programas de atuação dos educandos. Esse conhecimento deve percorrer o caminho da prática.

\section{Considerações finais}

Na obra Política e Educação, Paulo Freire evidenciao caráter político da educação, defendendo uma escola não dogmática; uma escola, portanto, não doutrinadora. Ele diz:

O respeito aos educandos não pode fundar-se no escamoteamento da verdade - a da politicidade da educação e na afirmação de uma mentira: a sua neutralidade. Uma das bonitezas da prática educativa está exatamente no reconhecimento e na assunção de sua politicidade que nos leva a viver o respeito real aos educandos ao não tratar, de forma sub-reptícia ou de forma grosseira, de impor-Ihes nossos pontos de vista. (FREIRE, 2007, p.40)

Desse modo, para ele, não existe conhecimento neutro e a leitura de mundo é uma ferramenta política na luta contra opressões e subjugação. Tais fundamentos solapam os argumentos basilares do Movimento Escola Sem Partido, que busca mascarar sua ligação orgânica com o status quo, isto é, com os princípios da economia de mercado e com o patriarcado.

Enquanto o pensamento freireano nos faz estranhar nossas práticas sociais, o Movimento Escola Sem Partido busca naturalizá-las, apresentando uma sociedade única, sem conflito de classes, de raça e de gênero. Além disso, o pensamento freireano enfatiza a estreita relação entre ensino e educação, educação e política, 


\section{Lusm \\ C.

ISSN: 1984-6444 | http://dx.doi.org/10.5902/1984644432996

ética e prática docente, enquanto o referido Movimento ignora a indissociabilidade dessas dimensões da vida humana.

Tais fatos explicam, em parte, a luta desse Movimento para desconstrução da imagem de Paulo Freire nos meios sociais e educacionais. Acusá-lo de doutrinador político, apresentar seu método como responsável pelos baixos resultados das escolas brasileiras nas avaliações educacionais internacionais constitui uma luta pelo senso comum, uma guerra cultural contra a escola pública, democrática e plural. Nesse contexto, podemos optar pela escolha de uma vertente conservadora, como a defendida pelo Movimento Escola Sem Partido, ou pela escolha de uma vertente emancipatória, como a defendida por Paulo Freire. Mas,nessa disputa simbólica, o que não podemos é ser neutro ou indiferente.

\section{Referências}

ARISTOTE. Politique.Trad. Jean Aubonnet. Paris: Les Belles Lettres, 1986.

BERTRAND, Yves; VALOIS, Paul. Paradigmas Educacionais: escola e sociedades. Lisboa: Instituto Piaget, 2001.

COMTE, Auguste. Discurso preliminar sobre o conjunto do positivismo. IN: COMTE, Os pensadores. São Paulo: Abril Cultural, 1978.

DINIZ FILHO, Luiz Lopes. Paulo Freire e a "educação bancária" ideologizada. In: Jornal Gazeta do Povo, 15/02/2013. Disponível em: http://www.escolasempartido.org/artigos-top/382-paulo-freire-e-a-educacaobancaria-ideologizada. Acesso em: 25 out 2017.

FERNANDES, Maria Dilnéia Espíndola. O percurso político-legislativo do programa "Escola sem partido" em Campo Grande, MS. ETD - Educação Temática Digital, v.19, p.217-235, jan./mar., $2017 . \quad$ Disponível em: https://periodicos.sbu.unicamp.br/ojs/index.php/etd/article/view/8647432. Acesso em: 29 out. 2017.

FREIRE, Paulo. Alfabetização: leitura do mundo, leitura da palavra. Trad. Lólio Lourenço de Oliveira. São Paulo: Paz e Terra, 2011.

FREIRE, Paulo. Política e educação. 8.ed. São Paulo: Villa das Letras, 2007.

FREIRE, Paulo. Educação como Prática da Liberdade. 27.ed. Rio de Janeiro: Paz e Terra, 2003.

FREIRE, Paulo.Pedagogia do Oprimido.São Paulo: Paz e Terra, 2001. 


\section{Lusm

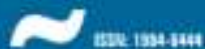

ISSN: 1984-6444 | http://dx.doi.org/10.5902/1984644432996

FREIRE, Paulo. Pedagogia da Autonomia: saberes necessários à prática educativa. Rio de Janeiro: Paz e Terra, 2017.

FREIRE, Paulo. A importância do ato de ler: em três artigos que se completam. 23ed. São Paulo: Cortez, 1989.

GOHN, Maria da Glória. Teorias dos movimentos sociais: paradigmas clássicos e contemporâneos. São Paulo: Loyola, 1997.

HUSSERL, Edmund. A crise das ciências europeias e a fenomenologia transcendental. Rio de Janeiro: Forense Universitária, 2012.

LACEY, Hugh. A imparcialidade da ciência e as responsabilidades dos cientistas. Scientiæstudia, São Paulo, v. 9, n. 3, p. 487-500, 2011.

LACEY, Hugh. O lugar da ciência no mundo dos valores e da experiência humana. Scientiæstudia, São Paulo, v. 7, n. 4, p. 681-701, 2009.

MOREIRA, Armindo. Professor não é educador. 3ed. Editora Edesio, 2013.

NOVAIS, Carlos Eduardo. Supermercado: Catedral do Consumo. Disponível em http://vintagesc94.blogspot.com.br/2010/05/supermercados-as-catedrais-doconsumo.html. Acesso em: 29 out. 2017.

OLIVEIRA, Marcos Barbosa. Neutralidade da ciência, desencantamento do mundo e controle da natureza. Scientiæstudia, São Paulo, v. 6, n. 1, p. 97-116, 2008.

OLIVEIRA, Nythamar de. Husserl. In: PECORARO, Rossano (org.) Os filósofos: Clássicos da Filosofia. Rio de Janeiro: Vozes, 2008a, Vol. II, p.231-253.

RESENDE, Leandro. 'Escola sem partido' quer fim da 'doutrinação de esquerda'. In: Jornal O Dia, 06/09/2015. Disponível em: http://odia.ig.com.br/noticia/brasil/2015-0906/escola-sem-partido-quer-fim-da-doutrinacao-de-esquerda.html. Acesso em: 25 out. 2017.

RIBEIRO, Vera Masagão. Apresentação. In: AÇÃO EDUCATIVA (Org.). A ideologia do movimento Escola Sem Partido: 20 autores desmontam o discurso. São Paulo: Ação Educativa, 2016.

SILVA, Tomaz Tadeu. Identidades Terminais: as transformações na política da pedagogia e na pedagogia da política. Rio de Janeiro: Vozes, 1996.

SODRÉ, Muniz. Comunicação do Grotesco: um ensaio sobre a cultura de massa no Brasil.Rio de Janeiro: Vozes, 1986. 
ISSN: 1984-6444 | http://dx.doi.org/10.5902/1984644432996

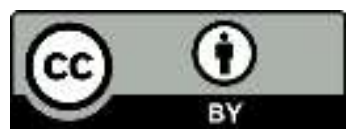

This work is licensed under a Creative Commons Attribution 4.0 International (CC BY 4.0). 